\title{
Early term labors: approach principles at 37-39 weeks of gestation
}

\author{
Mekin Sezik \\ Department of Obstetrics \& Gynecology, Faculty of Medicine, Siileyman Demirel University, Isparta, Turkey
}

\begin{abstract}
By bringing up the idea for discussion that fetal maturity is reached as of 37 weeks of gestation, the period covering $37+0 / 7$ up to $38+6 / 7$ weeks of gestation was defined as "early term". Morbidity and mortality rates are higher in infants born at early term than those born at 39-40 weeks of gestation. The mortality rates of those born at early term may also increase at early childhood and young adulthood. In this regard, labor induction or cesarean labor without any medical foundation at 37-39 weeks of gestation should be avoided. Since maintaining pregnancy in the presence of some complications may increase serious risks such as bleeding, uterine rupture, stillbirth or similar risks, it may be appropriate to plan and carry out the labor before 39 weeks of gestation. In the current review, the significant ones of such cases have been discussed.
\end{abstract}

Keywords: Near term pregnancy, clinical management.

\section{Duration of Physiological Gestation}

Gestational duration in human beings varies significantly, even it is determined as of ovulation. In a recent research, 125 singleton pregnancies were monitored by close follow-up of various hormonal markers and mean duration for term labors from ovulation up to delivery was determined as $268 \pm 9$ days ( 38 weeks and 2 days). In the same study, mean period for term labors as of last menstrual period and implantation was found as $285 \pm 13$ and $269 \pm 9$ days, respectively. ${ }^{[1]}$ Also, it was shown that the deliveries of one woman occurred at same gestational age. ${ }^{[1]}$ Therefore, it can be considered that each pregnancy probably has a "programmed"

\section{Özet: Erken term doğumlar: 37-39. haftalarda} yaklaşım prensipleri

Fetal matüritenin 37. gebelik haftası itibari ile sağlandığı fikrinin tartışmaya açılması ile 37+0/7 ila 38+6/7 gebelik haftalarını kapsayan dönem "erken term" olarak isimlendirilmiştir. Erken term dönemde doğan bebeklerde, morbidite ve mortalite oranları 39-40. haftalarda doğanlara göre daha fazladır. Ayrıca, erken termde doğanların erken çocukluk ve genç erişkinlik dönemlerinde de mortalite oranları artabilir. Bunlara dayanarak, 37-39. haftalarda tıbbi dayanağı olmayan doğum indüksiyonu veya sezaryen doğumlardan kaçınılmalıdır. Bazı komplikasyonların varlığında ise gebeliğin devamı; kanama, uterin rüptür, ölü doğum ve benzeri ciddi riskleri artırabildiğinden 39 hafta öncesinde doğumun planlanıp gerçekleştirilmesi yerinde olabilir. Mevcut derlemede bu durumların önemlileri tartışılmıştır

Anahtar sözcükler: Erken term gebelik, klinik yönetim.

duration being affected significantly by maternal factors.

Classically, it was thought that fetus "maturated" and "appropriate time" had come for delivery after 37 weeks of gestation. However, it has been shown in the recent years that carrying out delivery before its "programmed" period due to medical or non-medical reasons had some risks, and it has been brought up the idea for discussion that fetal maturity is reached as of 37 weeks of gestation. To this respect, the period covering $37+0 / 7$ up to $38+6 / 7$ weeks of gestation was defined as "early term". ${ }^{[2]}$ It is known that about $20 \%$ of the singleton and live births without any complication (18\% in North Carolina Early
Correspondence: Mekin Sezik, MD. Süleyman Demirel Üniversitesi Tip Fakültesi, Kadın Hastalıkları ve Doğum Anabilim Dalı, Isparta, Turkey.

e-mail: msezik@yahoo.com

Received: February 13, 2014; Accepted: May 5, 2014
Available online at: www.perinataljournal.com/20140223004 doi:10.2399/prn.14.0223004 QR (Quick Response) Code: 
Pregnancy Study; median duration of gestation is 262 days) occurs at 37-39 weeks of gestation. ${ }^{[1]}$

\section{Short-term Outcomes in Early Term Labors}

Morbidity and mortality rates are higher in infants born at early term than those born at 39-40 weeks of gestation. ${ }^{[3,4]}$ In an analysis covering 16 hospitals, it was seen that $26,199(34.6 \%)$ out of 75,625 labors were early term and 49,426 (65.4\%) of them were term labors. While morbidity and mortality rates were higher in infants born at early term than those born at 3941 weeks of gestation, difference was observed among the hospitals in terms of approaches and rates. ${ }^{[3]}$

The change in newborn morbidity rates according to the week of gestation in 264 health pregnancies without any additional problem except spontaneous preterm labor are seen in Fig. $1 .^{[5]}$ It was calculated that neonatal morbidity decreased $23 \%$ in the newborns for each 1 week of gestation proceeding between 32 and 39 weeks of gestation. ${ }^{[5,6]}$ The change of different neonatal morbidity categories according to the delivery week in the same study ${ }^{[5]}$ was summarized in Fig. 2. It is observed that the rate of neonatal hyperbilirubinemia at 37 weeks of gestation is similar to the rate at 35 weeks of gestation (about 20\%) (Fig. 2).

When deliveries at 39 week of gestation are taken as reference, the mortality rate in babies born at 37 and 38 weeks of gestation increases 1.9 (confidence interval: 1.8-2.0) and 1.2 (confidence interval: 1.2-1.3) times, respectively. ${ }^{[7]}$ While newborn mortality rate at 39 and 40 weeks of gestation is 0.8 per thousand, it is 1.7 per thousand at 37 weeks of gestation and 1.0 per thousand at 38 weeks of gestation. ${ }^{[7]}$

\section{Long-term Outcomes in Early Term Labors}

It was shown that the mortality rates of those born at early term increase at early childhood (between 1- and 5 -year-old) and young adulthood (between 18- and 36year-old) periods. ${ }^{[8]}$ In a wide study analyzing Swedish civil registries $(683,837$ singleton live births between 1973 and 1979), it was found that the mortality rates of those born at early term increased at neonatal (2.2 times), post-neonatal (1.7 times), early childhood (1.3 times) and young adulthood (1.1 times) periods compared to those born at 39-42 weeks of gestation. ${ }^{[8]} \mathrm{A}$ significant number of deaths at young adulthood (between 18- and 36-year-old) of those born at early term were

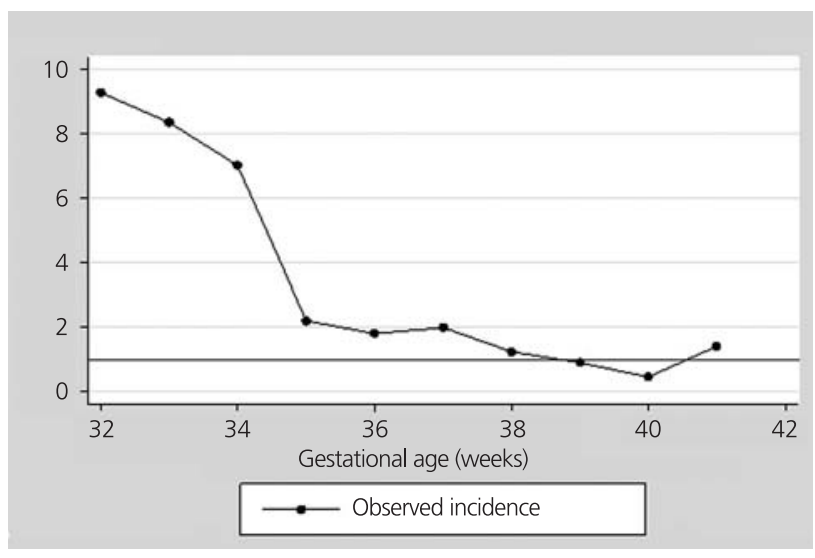

Fig. 1. Combined neonatal results according to the week of gestation ${ }^{[5]}$ (Adapted from 'Bastek JA, Sammel MD, Paré E, Srinivas SK, Posencheg MA, Elovitz MA. Adverse neonatal outcomes: examining the risks between preterm, late preterm, and term infants. Am J Obstet Gynecol 2008;199: 367.e1-8.' with kind permission from Elsevier; license no.: 3327541308429).

associated with congenital cardiovascular malformations and diabetes. Maternal diabetes causes preterm birth and long-term risk of diabetes in fetus. Also, it is known that congenital malformations are associated with preterm labor. Therefore, the reason of the slight increase in mortality risk between 18- and 36-year-old may not be due to "early term labors". However, such

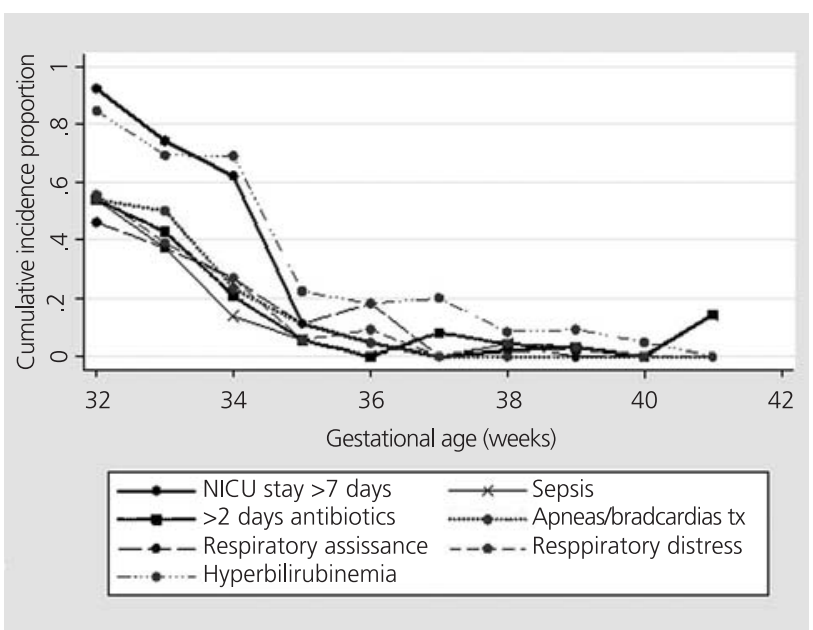

Fig. 2. The frequency of different neonatal results according to the week of gestation ${ }^{[5]}$ (Adapted from 'Bastek JA, Sammel MD, Paré E, Srinivas SK, Posencheg MA, Elovitz MA. Adverse neonatal outcomes: examining the risks between preterm, late preterm, and term infants. Am J Obstet Gynecol 2008;199: 367.e1-8.' with kind permission from Elsevier; license no.: 3327541308429). 
findings indicate that early term labors may have longterm risks even indirectly.

The long-term impacts of early term labors may not be limited with the increase of mortality rate. In a wide epidemiologic study (United Kingdom Millennium Cohort Study, $n=7650$ ), it was shown that the education success of 5-year-old children born at early term was lower. ${ }^{[9]}$ While "excellent level of success" in the evaluation scale was $45 \%$ In the children born at full term (3941 weeks), this rate was found as $41 \%$ in those born at 37-38 weeks. The authors emphasize that the risk is significant and "real" although the impact of early term labors is minor compared to other risk factors (risk rate: 1.05; confidence interval: $1.00-1.11) \cdot{ }^{[9]}$ It was reported in the 17-year formative study carried out in Australia (West Australia Gestational Cohort Study, $n=2900$ ) that the risk for having behavioral problems during childhood and even adolescent periods in babies born within 37 weeks of gestation increased independently of many factors compared to those born at 39 weeks of gestation and later (probability ratio: 1.43; confidence interval: 1.02-2.01).$^{[10]}$ A similar impact was not shown for those born at 38 weeks (probability rate: 1.00; confidence interval: $0.77-1.30){ }^{[10]}$

These new data support increase in morbidity and mortality in short- and long-term in those born at early term. ${ }^{[7-11]}$ In addition, it is thought that considering 37 and probably 38 weeks of gestation as "term" may cause undesired impacts in the mid- and long-term in terms of the child's mental health. In this regard, it is recommended to avoid labor induction or cesarean labor without any medical foundation at 37-39 weeks of gestation. ${ }^{[7]}$

\section{Medically Indicated Early Term Labors}

In case of a series of maternal, fetal and placental complications, carrying out the labor at early term may be necessary. It is required to customize labor decision and to balance current risks with undesired impacts associated with early term labor. ${ }^{[1,12]}$ In other words, there must be one or more "medical foundation" in order to carry out the delivery before 39 weeks of gestation.

Despite this fact, it is considered that the labor induction is used in practice at a rate more than expected. Therefore, "medical foundation" is relatively an obscure term. Current data indicate that the terms such as "medical foundation" or "medical indication" may be abused as a "tool" to induce labor before its physiological timing. For instance, one fourth of pregnancies in the USA is induced before the labor. ${ }^{[13,14]}$ And two third of them are stated as "term inductions". ${ }^{[13]}$ Also, the inductions particularly after 37 weeks of gestation tend to increase over the years (Fig. 3) ${ }^{\left[{ }^{[13]}\right.}$ It was seen that the induction rates as five-year periods increased constantly in deliveries over 37 weeks of gestation (Fig. 3). ${ }^{[13]}$ Again, according to the USA National Life Statistics 2010, induction rates at and above 37 weeks of gestation reached to $25 \%$ in 2005 which were about $10 \%$ in $1990 .^{[14]}$ It is calculated that about $8-10 \%$ of early term labors are elective which means that they are secondary to the induction without being based on any medical or obstetric indication. ${ }^{[15]}$

Consequently, it should be aimed to decrease early term induction and labor rates considered to be unnecessarily high without putting the health of mother and baby at risk in the presence of various gestational complications. To do so, it is significant to determine, know and apply the evidence-based medical indications of labors at early term. Indeed, carrying out delivery earlier in certain circumstances may be suggested for "optimal" results. Below, the significant ones of such circum-

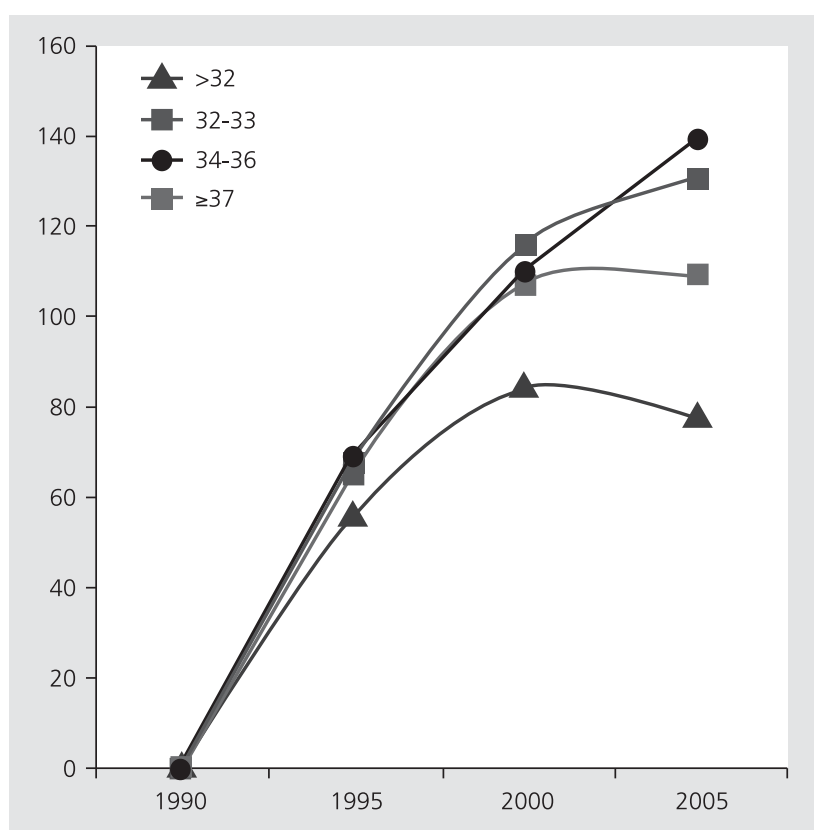

Fig. 3. Percentage changes in labor induction rate between 1990 and 2005 in the USA ${ }^{[13]}$ (Adapted from 'Chauhan SP, Ananth CV. Induction of labor in the United States: a critical appraisal of appropriateness and reducibility. Semin Perinatol 2012;36:336-43' with kind permission from Elsevier; license no.: 3327560675878). 
stances are given briefly as subtopics and recommendations are summarized in Table $\mathbf{1}$.

\section{Multiple Pregnancies}

In monochorionic diamniotic (MCDA) twin pregnancies, the risk of sudden infant death becomes clear after 34 weeks of gestation. Sudden transfusion and hypotensive attacks secondary to vascular anastomoses in the placenta are accounted for such losses. Based on these data, it is recommended to plan delivery in MCDA twins at 34-37 weeks of gestation. It is considered that the best week of gestation for delivery in non-complicated dichorionic twin pregnancies is 38 weeks of gestation ${ }^{[12,16]}$ Death of one twin causes a complication situation to follow up. The loss of a twin in monochorionic pregnancies is excluded from this review study. However, it is agreed that it can be waited until 37 weeks of gestation in dichorionic pregnancies. ${ }^{[16]}$

\section{Late-Onset Mild Gestational}

\section{Hypertension/Preeclampsia}

It was shown in these cases that labor induction at 37 weeks of gestation may decrease maternal complications without increasing cesarean section rate or newborn complications. ${ }^{[17,18]}$ As seen in Table 2, maternal morbidity is decreased for almost $30 \%$ by induction at early term. Also by this approach, it was found that there was no increase in neonatal morbidity (Table 2). Consequently, current data indicate that labor should not be delayed in gestational hypertension/preeclampsia at 37 weeks of gestation and later. However, in the presence of the following conditions, it will not be appropriate to wait for 37 weeks of gestation: (1) Severe hypertension, (2) preterm labor or membrane rupture, (3) vaginal bleeding, (4) corruption of fetal well-being (fetal growth retardation and/or oligohydramnios, variable/ late decelerations, loss of end diastolic flow or reverse flow, biophysics score $\leq 6){ }^{[18]}$

\section{Fetal Growth Retardation (FGR)}

Late-onset fetal growth retardation seems to be responsible for $50 \%$ of stillbirths unpredicted at term. There is a delicate balance in the presence of fetal growth retardation. Fetal growth retardation and the approach on this matter is out of the scope of this study; however, if fetal growth continues and Doppler
Table 1. Gestational complications for which medically indicated early labor is recommended and suggested weeks of gestation.

\begin{tabular}{|c|c|}
\hline Complication & $\begin{array}{l}\text { Suggested week } \\
\text { of gestation* }\end{array}$ \\
\hline Oligohydramnios & $36-37$ \\
\hline \multicolumn{2}{|l|}{ Maternal chronic hypertension } \\
\hline Not requiring antihypertensive treatment & $38-39$ \\
\hline Under control by antihypertensive treatment & $37-39$ \\
\hline Hard to control by antihypertensive treatment & $36-37$ \\
\hline Gestational hypertension & $37-38$ \\
\hline \multicolumn{2}{|l|}{ Preeclampsia } \\
\hline Severe & 34 \\
\hline Mild & 37 \\
\hline \multicolumn{2}{|l|}{ Diabetes + pregnancy (pregestational) } \\
\hline Well-controlled & $>39$ \\
\hline Vascular involvement & $37-39$ \\
\hline Could not be controlled & 34-39 (customize) \\
\hline \multicolumn{2}{|l|}{ Gestational diabetes } \\
\hline $\begin{array}{l}\text { Well-controlled by diet or } \\
\text { pharmacological treatment }\end{array}$ & $\begin{array}{l}\text { Usually }>38 \\
\text { (customize) }\end{array}$ \\
\hline Could not be controlled & 34-39 (customize) \\
\hline \multicolumn{2}{|l|}{ Multiple pregnancy } \\
\hline Dichorionic diamniotic (no additional complication) & 38 \\
\hline Monochorionic diamniotic (no additional complication) & $34-37$ \\
\hline Death of single twin & Delivery if $>34-36$ \\
\hline Monochorionic monoamniotic & $32-34$ \\
\hline Dichorionic diamniotic + selective IUGR & $36-37$ \\
\hline Dichorionic diamniotic + selective IUGR + abnormal & $32-34$ \\
\hline \multicolumn{2}{|l|}{ Doppler or maternal complication } \\
\hline Monochorionic diamniotic + selective IUGR & $32-34$ \\
\hline \multicolumn{2}{|l|}{ Fetal growth retardation, IUGR (singleton pregnancy) } \\
\hline No additional complication/finding & $38-39$ \\
\hline $\begin{array}{l}\text { Additional complication/finding available (abnormal } \\
\text { Doppler or Oligohydramnios or maternal complication) }\end{array}$ & $34-37$ \\
\hline Fetall wellness at risk & Emergency delivery \\
\hline Placenta previa & $36-37$ \\
\hline Placenta accreta/increta/percreta & $34-35$ \\
\hline \multicolumn{2}{|l|}{ Previous cesarean history } \\
\hline 2 times & 38 \\
\hline 3 or more & 37 \\
\hline Vertical (upper segment classical) incision & $36-37$ \\
\hline Previous myomectomy history & 37-38 (customize) \\
\hline Unexplained stillbirth history & >39 (customize) \\
\hline Current fetal congenital anomaly & 34-39 (customize) \\
\hline
\end{tabular}

*Within the week specified according to last menstrual period (i.e. 36-37 weeks: within 36+0/7 - 37+6/7). IUGR: intrauterine growth retardation

parameters are normal, close follow-up and continuation of pregnancy are recommended. If fetal growth stops and there are abnormal Doppler findings, delivery should be considered. In singleton pregnancies, it is recommended to plan delivery at 38-39 weeks after close follow-up. ${ }^{[12]}$ In some resources, it is stated that the delivery should be carried out at 37-38 weeks of 


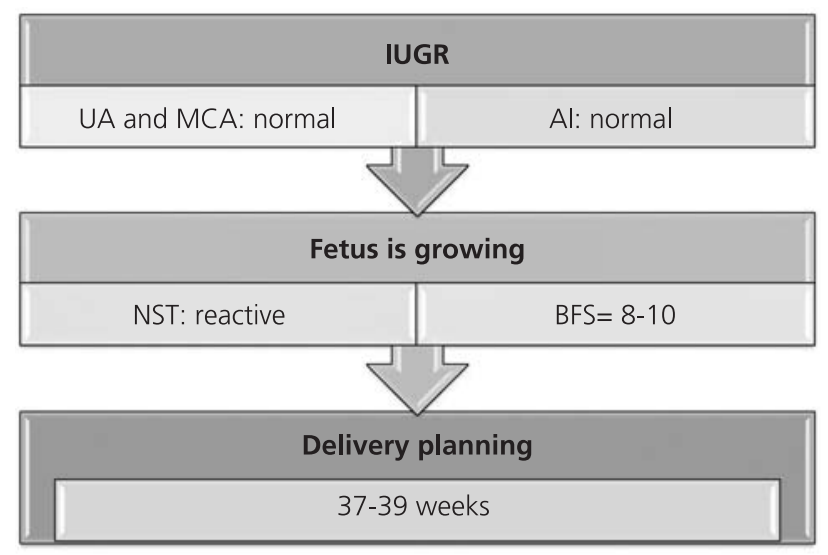

Fig. 4. Basic approach for fetal growth retardation (Al: amniotic index, BPS: biophysics score; IUGR: intrauterine growth retardation; MCA: middle cerebral artery; NST: non-stress test; UA: umbilical artery).

gestation. $^{[19]}$ A simplified algorithm for fetal growth retardation has been provided in Fig. 4.

\section{Previous Cesarean History}

In pregnancies which undergone more than two cesarean sections (repeating cesarean), waiting for 39 weeks of gestation may increase maternal complication rates depending on emergency cesarean section. In a recent and wide $(n=6435)$ research, ${ }^{[20]}$ it was shown that waiting for 39 weeks of gestation in those with 2 previous cesarean section increased maternal morbidity 3 times; however, no difference was found in perinatal results. Based on these findings, planned cesarean section is recommended at 38 weeks of gestation for those having 2 previous cesarean sections and at 37 weeks of
Table 2. The comparison of induction and waiting approaches at early term period in late-onset mild gestational hypertension/ preeclampsia cases in terms of maternal and neonatal outcomes. ${ }^{[18]}$

\begin{tabular}{lccc} 
Result & $\begin{array}{c}\text { Waiting } \\
\mathbf{n = 3 7 9} \\
>\mathbf{3 6}\end{array}$ & $\begin{array}{c}\text { Induction } \\
\mathbf{n = 3 7 7} \\
\mathbf{3 6 + 0 / 7}\end{array}$ & $\begin{array}{c}\mathbf{R R} \\
(\% 95 \mathrm{Cl})\end{array}$ \\
\hline Total maternal morbidity & $164(\% 44)$ & $117(\% 31)$ & 0.71 \\
HELLP syndrome & $11(\% 3)$ & $4(\% 1)$ & \\
Pulmonary edema & $2(\% 1)$ & - & \\
Abruptio placentae & - & - & \\
Eclampsia & - & - & \\
Maternal intense care & $14(\% 4)$ & $6(\% 2)$ & \\
Cesarean section & $72(\% 19)$ & $54(\% 14)$ & 0.75 \\
Total neonatal morbidity* & $32(\% 8)$ & $24(\% 6)$ & $(0.55-1.04)$ \\
Perinatal death* & - & - & \\
5-minute Apgar $<7^{*}$ & $9(\% 2)$ & $7(\% 2)$ & \\
Cord pH < $<7^{*}$ & $19(\% 6)$ & $9(\% 3)$ & \\
NICU need* & $8(\% 2)$ & $10(\% 3)$ & \\
Respiratory distress syndrome* & $1(\% 0.25)$ & $1(\% 0.25)$ & \\
\hline
\end{tabular}

*No significant difference. Cl: confidence interval; HELLP: hemolysis, elevated liver enzmes, low platelets; NICU: neonatal intense care unit; RR: risk rate (Adapted from 'Sibai BM. Management of late preterm and early-term pregnancies complicated by mild gestational hypertension/pre-eclampsia. Semin Perinatol 2011;35: 292-6.' with kind permission from Elsevier; license no.: 3334170176756).

gestation for those having 3 or more cesarean sections. $^{[20]}$

\section{Vertical Incision or Myomectomy History}

Uterine rupture risk is between 1 and $12 \%$ in pregnancies which had vertical (classical) uterine incision in previous cesarean section. ${ }^{[2]}$ The rupture includes serious risks such as maternal hypovolemic shock, stillbirth and fetal

Table 3. The comparison between maternal and neonatal morbidity rates in women with type 1 diabetes and gestational diabetes and those having normal glucose tolerance. ${ }^{[22]}$

\begin{tabular}{|c|c|c|c|c|c|c|}
\hline & $\begin{array}{c}\text { Type } 1 \text { DM }(\%) \\
(n=5089)\end{array}$ & $\begin{array}{c}\text { Non-DM (\%) } \\
(n=1,260,207)\end{array}$ & $\begin{array}{c}p \\
\text { value }\end{array}$ & $\begin{array}{c}\text { GDM (\%) } \\
(n=10,525)\end{array}$ & $\begin{array}{l}\text { Non-GDM (\%) } \\
(n=1,249,772)\end{array}$ & $\begin{array}{c}\mathbf{p} \\
\text { value }\end{array}$ \\
\hline Preeclampsia & 9.7 & 2.0 & $<0.05$ & 5.9 & 2.6 & $<0.001$ \\
\hline Delivery at $<37$ & 21.0 & 5.1 & $<0.05$ & 8.6 & 5.0 & $<0.001$ \\
\hline RDS & 1.0 & 0.2 & $<0.05$ & 0.3 & 0.2 & N.D. \\
\hline LGA & 31.0 & 3.6 & $<0.05$ & 15.1 & 3.6 & $<0.001$ \\
\hline Erb's palsy & 2.1 & 0.25 & $<0.05$ & 0.7 & 0.2 & $<0.001$ \\
\hline Stillbirth & 1.5 & 0.3 & $<0.05$ & 0.4 & 0.3 & N.D. \\
\hline
\end{tabular}

DM: diabetes mellitus; GDM: gestational diabetes; LGA: large-for-gestational age (>90 percentile); N.D.: statistically no difference; RDS: respiratory distress syndrome (Adapted from 'Catalano PM, Sacks DA. Timing of indicated late preterm and early-term birth in chronic medical complications: diabetes. Semin Perinatol 2011;35:297-301.' with kind permission from Elsevier; license no.: 3332390119905$)$. 
hypoxy-acidosis. Therefore, cesarean section is recommended at 36-37 weeks of gestation for those having vertical incision. Due to similar reasons, carrying out delivery at 37-38 weeks of gestation can be recommended in case of pregnancies in uterus with myomectomy. ${ }^{[12,21]}$

\section{Maternal Diabetes}

The timing of delivery in diabetic pregnancies is controversial and the risks for fetal loss, macrosomia and labor trauma may increase by "waiting" (Table 3). Early term labor is not recommended for those who are under good glycemic control by diet or pharmacological treatment and those found to have fetal weight below 90 percentile. ${ }^{[2]}$ In other case, early term labor may be planned by considering maternal and fetal conditions (Table 1).

\section{Placenta Previa and Accreta}

The rates of emergency bleeding according to the week of gestation in placenta previa are given in Table 4. ${ }^{[23]}$ In a decision analysis study ${ }^{[23]}$ considering the severity of bleeding associated with previa, delivery at 36-37 weeks of gestation is recommended in non-complicated previa. In accreta cases established with antenatal diagnosis, the rate of the risk for serious bleeding and emergency surgery is $44 \%$ even at 36 weeks of gestation; $;^{[2]}$ therefore, it may be recommended to plan delivery at 34-35 weeks of gestation following antenatal corticosteroid application.

\section{Stillbirth History}

Fetal losses at third trimester are a critical issue for family and physician. Also, there is a recurrence risk from 2 up to 10 times (totally 1-6\%).

However, it is considered that carrying out delivery before 39 weeks of gestation does not help to prevent recurrent stillbirth or other complications if other indications do not exist under appropriate follow-up. ${ }^{[25]}$ Yet, family and physician have significant anxiety in stillbirth case. In this case, it may be considered to plan delivery at 38 weeks of gestation. ${ }^{[25]}$

\section{Fetal Anomalies}

There is a fetal anomaly in $2-3 \%$ of all pregnancies. However, in many fetal anomalies, changing the time of delivery does not help; on the contrary, it will cause
Table 4. Emergency bleeding rates at different weeks of gestation in placenta previa.

\begin{tabular}{cc} 
Week of gestation & Percentage of emergency bleeding \\
$35+$ & $\% 4.7$ \\
$36+$ & $\% 15$ \\
$37+$ & $\% 30$ \\
$38+$ & $\% 59$ \\
\hline
\end{tabular}

additional problems. Yet, "customized approach" should be adopted in the light of antenatal consultations preferably for each case (i.e. pediatric cardiology or brain surgery). ${ }^{[26]}$ Delivery may be planned at early term in the presence of progressive fetal organ damage, fetal complication risk (i.e. intracranial hemorrhage at vein of Galen aneurysmal malformation) or additional maternal complication. ${ }^{[12,26]}$ Although it is rare, delivery should be planned in case of "mirror syndrome".

\section{Conclusion}

Short- and long-term mortality and morbidity rates increase in those born at early term (37-39 weeks of gestation). To this respect, planning delivery without medical indication at early term will not be an appropriate approach. Since maintaining pregnancy in the presence of some complications may increase serious risks such as bleeding, uterine rupture, stillbirth or similar risks, it may be appropriate to plan and carry out the labor before 39 weeks of gestation (Table 1).

Conflicts of Interest: No conflicts declared.

\section{References}

1. Jukic AM, Baird DD, Weinberg CR, McConnaughey DR, Wilcox AJ. Length of human pregnancy and contributors to its natural variation. Hum Reprod 2013;28:2848-55.

2. Fleischman AR, Oinuma M, Clark SL. Rethinking the definition of "term pregnancy". Obstet Gynecol 2010;116:1369.

3. McAlister BS, Tietze M, Northam S. Early term birth: the impact of practice patterns on rates and outcomes. West J Nurs Res 2013;35:1026-42.

4. Arslan E, Demirkaya HU, Erdoğan F, Gücüyener N, Gülşen B. Erken term bebeklerde morbidite ve emzirme süresinin araştırılması. Marmara Medical Journal 2013;26(S1):MP307.

5. Bastek JA, Sammel MD, Paré E, Srinivas SK, Posencheg MA, Elovitz MA. Adverse neonatal outcomes: examining the 
risks between preterm, late preterm, and term infants. Am J Obstet Gynecol 2008;199:367.e1-8.

6. Engle WA. Morbidity and mortality in late preterm and early term newborns: a continuum. Clin Perinatol 2011;38: 493-516.

7. American College of Obstetricians and Gynecologists. ACOG committee opinion no. 561: Nonmedically indicated early-term deliveries. Obstet Gynecol 2013;121:911-5.

8. Crump C, Sundquist K, Winkleby MA, Sundquist J. Earlyterm birth (37-38 weeks) and mortality in young adulthood. Epidemiology 2013;24:270-6.

9. Quigley MA, Poulsen G, Boyle E, Wolke D, Field D, Alfirevic Z, et al. Early term and late preterm birth are associated with poorer school performance at age 5 years: a cohort study. Arch Dis Child Fetal Neonatal Ed 2012;97: F167-73.

10. Robinson M, Whitehouse AJ, Zubrick SR, Pennell CE, Jacoby P, McLean NJ, et al. Delivery at 37 weeks' gestation is associated with a higher risk for child behavioural problems. Aust N Z J Obstet Gynaecol 2013;53:143-51.

11. Bassil KL, Shah PS, Shah V, Ye XY, Lee SK, Jefferies AL; and the Canadian Neonatal Network. Impact of late preterm and early term infants on Canadian neonatal intensive care units. Am J Perinatol 2013;31:269-78.

12. American College of Obstetricians and Gynecologists. ACOG committee opinion no. 560: Medically indicated late-preterm and early-term deliveries. Obstet Gynecol 2013;121:908-10.

13. Chauhan SP, Ananth CV. Induction of labor in the United States: a critical appraisal of appropriateness and reducibility. Semin Perinatol 2012;36:336-43.

14. United States Centers for Disease Control and Prevention. Vital Statistics Data: http://www.cdc.gov/nchs/data_access/ vitalstatsonline.htm.

15. Murthy K, Grobman WA, Lee TA, Holl JL. Trends in induction of labor at early-term gestation. Am J Obstet Gynecol 2011;204:435.e1-6.
16. Newman RB, Unal ER. Multiple gestations: timing of indicated late preterm and early-term births in uncomplicated dichorionic, monochorionic, and monoamniotic twins. Semin Perinatol 2011;35:277-85.

17. Koopmans CM, Bijlenga D, Groen H, et al; HYPITAT study group. Induction of labour versus expectant monitoring for gestational hypertension or mild pre-eclampsia after 36 weeks' gestation (HYPITAT): a multicentre, open-label randomised controlled trial. Lancet 2009;374:979-88.

18. Sibai BM. Management of late preterm and early-term pregnancies complicated by mild gestational hypertension/preeclampsia. Semin Perinatol 2011;35:292-6.

19. Galan HL. Timing delivery of the growth-restricted fetus. Semin Perinatol 2011;35:262-9.

20. Hart L, Refuerzo J, Sibai B, Blackwell S. Should the "39 week rule" apply to women with multiple prior cesarean deliveries? Am J Obstet Gynecol 2014;210:S27.

21. Spong CY, Mercer BM, D'alton M, Kilpatrick S, Blackwell S, Saade G. Timing of indicated late-preterm and early-term birth. Obstet Gynecol 2011;118:323-33.

22. Catalano PM, Sacks DA. Timing of indicated late preterm and early-term birth in chronic medical complications: diabetes. Semin Perinatol 2011;35:297-301.

23. Zlatnik MG, Little SE, Kohli P, Kaimal AJ, Stotland NE, Caughey AB. When should women with placenta previa be delivered? A decision analysis. J Reprod Med 2010;55:37381.

24. Robinson BK, Grobman WA. Effectiveness of timing strategies for delivery of individuals with placenta previa and accreta. Obstet Gynecol 2010;116:835-42.

25. Silver RM. Previous stillbirth, late preterm, and early-term birth. Semin Perinatol 2011;35:302-8.

26. Craigo SD. Indicated preterm birth for fetal anomalies. Semin Perinatol 2011;35: 270-6. 